Journal of Education and Vocational Research

Vol. 3, No. 7, pp. 216-224, July 2012 (ISSN 2221-2590)

\title{
Gathering Knowledge Standards of Principals, Determining their Importance from the viewpoint of Educational Administrators of Elementary Schools in Mashhad
}

\author{
Nazia Sadat Naseri*, Elham Fariborzi \\ Islamic Azad University, Mashhad, Iran \\ *naseri5588@mshdiau.ac.ir
}

\begin{abstract}
Education is the key factor for development in each country. It needs wise management. Application of human resource standards, including knowledge standards have led to a remarkable improvement in principals' performance and the progress of the country consequently. Researchers determined the knowledge standards for educational administrators of elementary schools in Mashhad due to the lack of them in Iran. Some of these knowledge standards of developed countries_and according to their importance in terms of principals are as follows: 1-Having knowledge related to ethical practices, 2- The application of technology to improve education, 3-Active community involvement by creating a shared responsibility and respond to the interests and needs of community members and parents by mutual cooperation and mobilize community resources in line with school success and student, 4-Reaction and the influence of cultural background, legal, economic, social, political in macro-level, 5- Having high expectations from students and staff, 6- Managing organization as efficient, operations and resources for efficient and effective learning environment, 7- Create, develop, express, implementation and monitoring of learning, insight and support, strengthen and sustain continuous learning culture in schools to enhance student's learning and staff's professional growth. The questionnaire had seven components and 69 items. Principals of elementary school in Mashhad gave a mark to each item. The results showed that the majority of participants in this study gave worth for principals' knowledge standards and their scores were between 19 and 20 out of 20. In addition, the fourth components had the highest priority based on them. It was to have the knowledge associated with the ethical practices. More results are subsequently explained in the paper.
\end{abstract}

Keywords: Knowledge Standards, Elementary School, Principals, Educational Administrators, Primary School

\section{Introduction}

In today's world, knowledge-based economy is a key element of developing countries. One way to benefit from knowledge-based economy is the investment in the education sector. Every community wants to move in this direction should train the human resources based on special framework and need to be guided them in the right direction to avoid wasting resources. Among these frameworks, standards that require continuous presence in the various fields of human life are included the areas of education that more than anything else is necessary. Education is the key factor in social, economical, cultural and political development in each community. It needs wise management. Application of human resource standards, including knowledge standards have led to a remarkable improvement in principals' performance and the progress of the country consequently (Gharai-Moghaddam, 1998). In this regard, researchers were seeking to study the knowledge standards for principals in other countries and ten to rank them in terms of the attitude of mangers of elementary schools in Mashhad, Iran to give some practical suggestions for educational improvement.

Educational standards by providing optimal quality of educational services, processes and the controls are affected by this system and expectations of service recipients, and ultimately cause the system to be supplied. Standards in the education system save the utilization of labor, energy, materials and equipment and facilities. In addition, these standards achieve developmental objectives through some steps in education. Reviewing the characteristics of education in different countries shows that elementary education is considered as the most important priority in education. Thus the elementary role in rising awareness generation is quite clear. It needs good management and leadership. Hence, based on the role of elementary education in the education system, it is necessary to know more about knowledge standards for principals in elementary school and implementing them. 
To study knowledge standards based on the importance of them by principals' perspectives of elementary schools in Mashhad and to develop them.

- What are the knowledge standards for principals in elementary school?

- What are the most important of knowledge standards for principals in elementary schools in Mashhad from their perspective?

\section{Theoretical Definitions}

Elementary school: Children 6 to 11-year period, which they are in school (Mofidi, 2007). It is the general course of education, compulsory and free, and the constitution of the Islamic Republic of Iran and it is five academic years (Farmyhny- Farahani, 2000).

Standard: Standard is a proof contains rules, guidelines or characteristics for activities or their results to public use and frequent that provided by unanimity and approved by the organization is known to recognize. It purposes to achieve a desirable level of discipline in a particular field (Yegane, 1999).

Knowledge standard: The knowledge required for each principal's ecnamrofrep standard (ISLLC, 2012)

Technology: Set of processes, methods, techniques, tools, equipments, machinery and skills that made products or offered services by them) Fathian, 2008)

Research background in Iran: Mahmudi (2005) in research titled "Preparing the performance standards for educational administrators in Tehran and giving a proper model" has developed a set of competencies of educational administrators includes six main components and forty sub-component and one hundred and sixty-treated demonstrate competence (performance indicators). In addition, Naseri (2006) in a study titled "Compilation performance standards of educational administrators in high school and provide a model for its application in Tehran" after reviewing the standards of developed countries and their localization considering to the duties of educational principals in Iran. Finally, she classified performance standards and then rates their importance from the perspective of principals to determine them for high school in Tehran. Then she did an analysis of variance and orthogonal rotation of components based on their importance from the viewpoint of the statistical population, and then the items were classified and named.

The standards of ISLLC organization in the United States (Interstate School Leaders Licensure Consortium, 2012): Principal is the instructional leader that prepares the success of all students through the following items:

- Standard 1: Facilitating the development, expression, execution and supervision on the insight that learning is supported by the school and with the participation of all members of the school, system has been set.

- Standard 2: Supporting, developing educational programs related to strengthening the school

- Standard 3: management, operations and resources for creating an effective learning environment, and safety was done.

- Standard 4: partnership with families and community members, responding to the needs of diverse communities community and mobilize community resources.

- Standard 5: The Truth according to equity and ethical manner.

- Standard 6: Understand and respond to cultural, legal, economical, social, political influences in macro level (Meyer, 2000).

Standards for Educational Leaders in Virginia: In standard 2, Principal is the educational leader of the success of all students is increasing by facilitating the development, implementation and monitoring of expression and insight learning and is supported by the school council is. Director should have knowledge and understanding in the following cases:

- Learning goals in a society with a multiplicity of parties (coalition party)

- Principles formulating and implementing strategic plans.

$\circ$ Systems theory. 
- Data sources, data collection and data analysis strategies

- Effective communication with others

- Effective consensus and negotiation skills

- At standard three, director of support, strengthen and maintain the school culture and instructional program for the management of student learning and staff professional growth.

- Principal has the ability to recognize and understand the following points:

- Growth and student achievement.

- Applied Learning theories.

- Applied Motivational theories.

- Designing, implementing, and evaluating and improving curriculum.

- Principles of effective teaching.

- Measurement and evaluation strategies.

- Importance of various educational programs.

- Models of adult learning and professional growth.

- Change process for systems, organizations and individuals.

- The role of technology in promoting student learning and professional growth.

- Types of school culture.

- The standard four-principal, Management of the organization, operation, budgets and resources to create an effective learning environment, ensures the efficient and safe.

Principal Knowledge and understanding are about the following:

- Theories and models of organizations and principles of organizational development.

- Operational procedures at the school and district level.

- Principles and issues related to school safety and security.

- Management and human resource development.

- Principles and issues related to fiscal operations of school management.

- Principles and issues related to school facilities and use of space.

- Legal issues affecting school operations.

- Existing technologies that support management functions.

The standard five is that principal should have cooperation with families and community council members and respond to the needs and interests of diverse communities, and mobilizing community resources to plan. Principal understands the knowledge as the following:

- Emerging issues and potential factors affecting the school.

- Dynamics of the diverse school environment.

- Community resources.

- Community relations and sales strategies and processes.

- Successful models of school engagement, family, business, community, government and higher education.

- In standard six, principal should have been honest and fair and behave by ethical way. Principal perceptions and knowledge's are the following:

- The purpose of education and leadership role in modern society.

- Various ethical frameworks and perspectives about ethics.

- Diverse social values in school.

- Rules of professional ethics.

- Philosophy and history education.

In standard seven, principal reacted to the cultural, legal, economic, social, and political affairs in macro level that affect the school and Interaction with it and will understand it. Principal Knowledge and understanding are the following:

- The school system reinforces the principles of choice. 
- The role of public education in a democratic society and a nation productive and economic development and modernization.

- Laws related to education and teaching.

- Economic systems, cultural, social, and political processes affecting the school.

- Change models and strategies and conflict resolution in the fields of economic, cultural, social, political affairs in macro-level.

- Global issues and forces influencing teaching and learning.

- Importance of diversity and equality in a democratic society.

Theoretical Foundations: Standardization: Standardization I to determine the permissible scope of measures and activities in a job or a series of jobs (Shermerhorn, 1997). In the other word, standardization is a process of determining and specifying a set of rules, regulations and procedures for performing each task and duty. Indeed, standardization determines the range of person's actions at work and shows direction to it. Key features of the standards are as follows:

- Standard represents are the most safety ،the best and easiest way operations.

- Standards are establishing the best way to maintain technical knowledge and show skills.

- Standards are the mechanism for measuring and performance evaluation of standards.

- Standards make clear the relationship between cause and effect.

- Standards are the base for maintenance and partial improvement. Accurate and complete compliance with standards

- Means that, system maintenance and improvement for the improvement work.

- Standards offer the basis of the training.

- Standards are a suitable basis for audit and conducive to the diagnosis.

The standards provide prevent data prevention of errors and decrease variables affecting the process are (Imaie, 2002). Necessity localization standards are as follow:

- Standards are not absolute concepts and non-changeable means they cannot see as the paradigm but be adapted or imitated it, or even naturalize and localization.

- They also sometimes must manipulate the plot and take into consideration the specific conditions of each country

- It is believed that sometimes should use criteria due to the geographical, cultural, economical, and social conditions in every country and region.

- Sometimes we cannot even look at the standards as country standards. Standards will need to look at regional until to respond the local needs.

- In this study, also researchers tried to develop standards of knowledge for elementary school principals in Mashhad.

\section{Methodology}

In this study, elementary school administrators' comments in connection with important components of knowledge standard was collected and described by questionnaire. Therefore, this study is descriptive.

Statistical population: Statistical population were elementary school administrators in Mashhad (four regions $(\mathrm{N}=110)$.

Size of statistical sample: By using the formula of Cochran (Delavar, 1997) was calculated. Samples of elementary school principals $(n=84)$ have been selected by random sampling technique.

Methods of collecting data: Methods of collecting data were library studies and using Internet search use of questionnaires in this study. Questionnaire for principal's knowledge standards has the seven components and some sub- components. Questionnaire was prepared with 69 items totally.

Methods of data analysis: For data, analysis was used descriptive statistics in this research. 


\section{Results}

Data from questionnaires in connection with the research question has been analysis using appropriate statistical methods. The process is as follows: Research question 1: What are the knowledge standards for educational administrators of elementary schools in Mashhad? Base on literature review these standards were studied by researchers and were extracted seven main components. These are components and subcomponents:

A. Create, develop, express, implementation and monitoring of learning, insight and support, strengthen and sustain continuous learning culture in schools to enhance student's learning and staff's professional growth.

- The learning objectives in a society with different parties

- The principle of preparing and implementing of strategic plans

- Systems theory

- The application of different sources of data as detection tools for evaluation, identification and the improvement of education

- The effective communication with students and staff

- The effective consensus and discussion skills

- The effective education principles

- Strategies for professional growth

- The growth steps of students

- The practical theories for learning

- The practical theories for motivation

- The designing, implementing, evaluating and improving of Curriculum

- The Strategies for evaluating, reviewing and assessing

- The theories for adult's learning and professional growth

- The process of changes for systems, organization and people

- The effects of the school culture on professional growth

- The role of leadership in modern society

- The various values of beneficiary persons of schools

- The principles of effective teaching

- Measuring and evaluating of strategies

- The significance of variety educational programs

- The kinds of scholastic culture

- Efficient management of the organization, operations and resources for efficient and effective learning environment

- Theories and models of organizations, growth principles and organizational development

- Operational procedures at the school and district level

- Principles and issues related to school safety and security

- Human resource development strategies

- Principles and issues related to fiscal operations of school management

- Principles and issues related to school facilities and use of space

- Principles to create and implement strategic plans

- Use of information resources in data collection and data analysis strategies for effective management

- Changing process systems, organizations and individuals

- Change models and strategies and conflict resolution

- Labor relations and contract strategies

- Human resource management and training

- Legal issues affecting school operations

- Principals of students notification of their duties, rules of reward and punishment and disciplinary regulations of the school according to their age, understanding and cooperation with relevant staff

- Principles relating to notifying school staff and to the provisions of laws banning corporal punishment in schools. 
B. Active community involvement by creating a shared responsibility and respond to the interests and needs of community members and parents by cooperation and mobilize community resources in line with success of school and students.

- Effective communication skills

- Conditions and global issues and dynamics that influence school

- Community resources (which can be used by school)

- Effective public relations strategies

- Effective use of marketing and communication strategies with the community

- Successful models of school engagement, family, business, economy, society, government and higher education

- Roles and responsibilities of school board governance

- Emerging issues and factors potentially affecting the school community

- Conditions and dynamics of the diverse school environment

C. having knowledge related to ethical practices

- The purpose of education

- Various ethical frameworks and perspectives about ethics

- Diverse social values in school

- Rules of professional ethics (such as having integrity, fairness, justice, commitment, energy and cooperative spirit at work)

- Philosophy and history education

- Provide value as a model for students and all stakeholders.

D. Reaction and the influence of cultural background, legal, economic, social, political in macro-level

- Iran's rules in relation to schools and education

- The role of public education in a democratic society and a nation productive and economic development and modernization

- Economic systems, cultural, social, and political processes affecting the school

- Change models and strategies and conflict resolution in the fields of economic, cultural, social, and political in macro-level

- Global issues and forces influencing teaching and learning

- The importance of ethnic diversity and equality in society

E. Application of technology to improve education

- The role of technology in schools as an integral part of professional growth

- $\quad$ Shaping how the labor market and sustainability through technology

- How the data support system based on technology

- Better operations and integrate technology in all relevant areas

- How to use technology for effective leadership

- The role of technology in improving student learning

F. Having high expectations of students and staff

Data analysis: Histogram below shows average scores for each respondent in connection with the items of the questionnaire related to the knowledge standards for principals. As you can see in Figure 1, the majority of knowledge standards for principals placed great importance and they scored between 19 and 20. 
Figure 1: The priorities of knowledge standards for principals

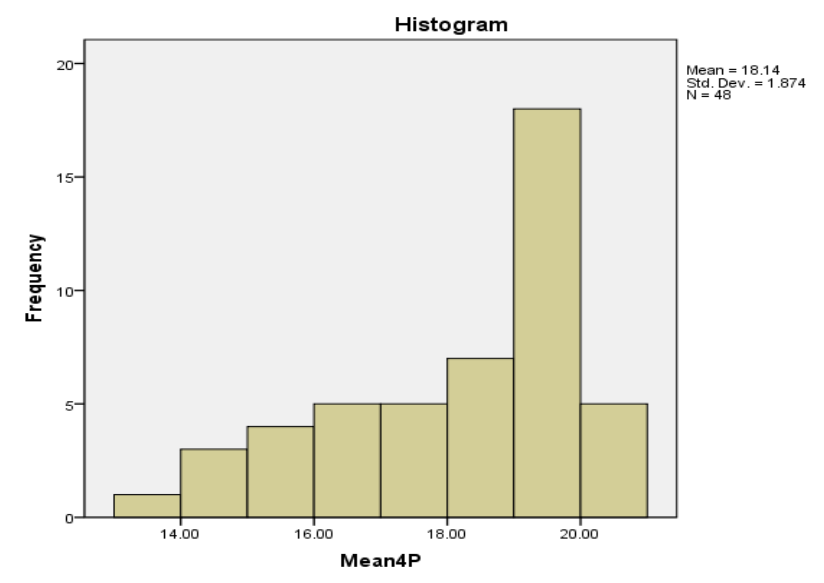

Figure 2: The average means scores for the respondent to each knowledge standard item

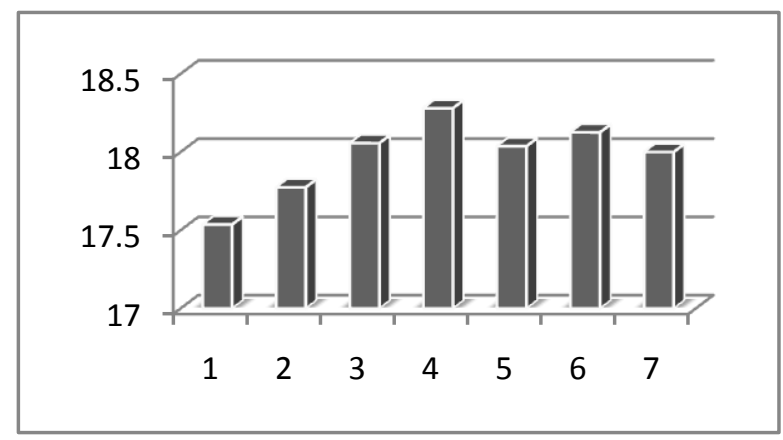

The Figure 2 shows the average mean scores for the respondent to each standard component of knowledge for principals and it shows the forth component mean" having knowledge related to ethical practices" were considered more important than other components by the respondents. According to their importance in terms of principals they are as follows: 1-Having knowledge related to ethical practices, 2- The application of technology to improve education, 3- Active community involvement by creating a shared responsibility and respond to the interests and needs of community members and parents by mutual cooperation and mobilize community resources in line with school success and student, 4 -Reaction and the influence of cultural background, legal, economic, social, political in macro-level, 5- Having high expectations of students and staff, 6- Efficient management organization, operations and resources for efficient and effective learning environment, 7- Create, develop, express, implementation and monitoring of learning, insight and support, strengthen and sustain continuous learning culture in schools to enhance student learning and staff professional growth.

\section{Conclusion}

Establishment of new international order in the twenty-first century could place the world on the strong basis. This request requires standard and this century is the century remedies. In the field of education and training that focus on people, it needs the standards more than other industries and it is felt. The community understood educational administration is a dynamic activity and its success is depends on the efficiency and effectiveness of its management. Therefore, researchers determined the knowledge standards for educational administrators of elementary schools in Mashhad due to the lack of standards for knowledge of principals in Iran.

Recommendations: According to the Iranian government under the Constitution is the only guardian of education students at three educational levels and trends of theoretical and professional; therefore, it is 
essential that executive authorities in education pay attention to the standardization topics for human resources. In addition, they make expert committee of elementary school principals and administrators to expand the standard of the knowledge for them. It will increase the levels of confidence in the quality of organizational activities and to prevent the waste of material resources, financial, and human. Preparing the evaluation forms according to the standards and related indicators and to design an efficient system for evaluation knowledge standards. It can be as important tool for the development of educational system to achieve the best quality of education. Developing accurate and professional standards require scientific support and careful study and applying the theories, models and excellent patterns of standardization and literature. It supports the axis of the standardization process and causes the safety factor that increased the degree of fit desirable scientific, local, national and international. So in preparing the standards, it is essential to observed it through the comparative studies, case studies and research local, national (native) and internationally. Review of the process in order to fix the distances between the required qualifications for the principals and the status. The development of the competency of principals to accept more responsibility for compliance with standards developed by the records of past or current training processes. Assessment of existing knowledge of principals for doing the tasks. Define training needs based on the analysis of the existing needs in school with compared with the knowledge of administrators. The funding for education. For total productivity in the education system and the standardization of its components in other subsystems, systems, and systems will be considered dependent. Empowerment of principals in achieving the necessary standards of knowledge is necessary and this requires the grounds for training them to improve knowledge in order to increase their tendency to apply standards.

\section{For training principals in the standardization of knowledge should be given to the following: \\ - Preparation of list of developed standards \\ - prepare the list of existing distance from them \\ - emphasize the importance of helping the organization for more effectiveness and efficiency in training \\ - explaining the learners about the nature of training and competence distance to meet the needs of the desired distances \\ - Corrective actions and training principals}

In this regard, there are limitations in the process of training principals that should be identified and listed as organizational policy approved; The financial condition; time requirements and timing; Educational resources and providers of accredited training to principals; legal requirements; participation, motivation and abilities of individual learners; and other logistical factors.

\footnotetext{
After training, the evaluation criteria and methods of management training is done by using the following measures:

- receive feedback from principals

- receive feedback from instructors

- Preparation of feedback reports for education

- The satisfaction of the learners

- knowledge, skills and behavior of learners

- job performance of learners during the real task

- Management of satisfied learners.

- The effects of teaching in schools

- The implementing procedures for monitoring the training process.

- The main purpose of monitoring is to ensure for achieving educational and organizational based on effectiveness and efficiency. Monitoring should be performed by competent personnel and organized according to administrative procedures; Staff involved in monitoring should be independent of their direct duties. For monitoring, may be used consultation, observation and data collection. Monitoring is more precious and valuable tool than the efficiency of education process.

Also the awareness of principals and motivate them to improve their knowledge through the alarming reports of the quality of the educational system is useful at this stage.
} 


\section{References}

Delavar, A. (1997). The Theoretical Principles and Scientific in Social and Educational Researches. Tehran: Roshd Press.

Farmyhny- Farahani, M. (2000). Descriptive Dictionary for Educational Studies. Tehran: Asrar Danesh Press.

Fathian, M. (2008). Principles of management and information technology, 6th Ed, Tehran, University of Science and Technology.

Gharai-Moghaddam, A. (1998). Educational Administration. Tehran: Abjad Press.

Imaie, M. (2002). Gembakizen. Tehran: Saiko Press.

ISLLC. (2012). Interstate School Leaders Licensure Consortium Standards. From: http://coe.fgcu.edu/faculty/valesky/isllcstandards.htm

Mahmudi, A. H. (2005). Preparing the performance standards for educational administration in Tehran and giving a proper model. Unpublished PhD thesis, Islamic Azad University: Sciences and Research, Tehran Branch.

Meyer, L. (2000). Standards For School Leaders, The NTA Resource Bulletin, from http: // ici . umn. Gdu /ncsgt/ public ptions/ntp/ bullgtins/ pprig-html.

Mofidi, F. (2007). Primary Education, $6^{\text {th }}$ ed. Tehran: Payam Noor University Press.

Naseri, N. S. (2006). Compilation performance standards of educational principals high school and provide a model for its application in Tehran. Unpublished PhD thesis, Islamic Azad University: Sciences and Research, Tehran Branch.

Shermerhorn, J. (1997). Organizational Behavior, 6th ed, John Wiley And Sons Ins Press.

Yegane, M. (1999). Standards and standardize. The center of education and industrial research press. 